\title{
RESEARCH
}

Open Access

\section{Ceramide induces MMP-9 expression through JAK2/STAT3 pathway in airway epithelium}

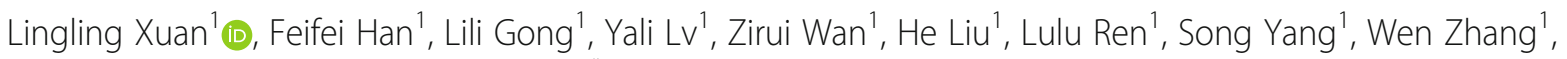
Ting Li ${ }^{2}$, Chunting $\operatorname{Tan}^{3}$ and Lihong Liu ${ }^{1 *}$

\begin{abstract}
Background: Ceramide, a bioactive lipid, plays an essential role in the development of several pulmonary inflammatory diseases. Matrix metallopeptidase 9 (MMP-9) regulates the synthesis and degradation of extracellular matrix, and is associated with airway remodeling and tissue injury. This study was conducted to investigate the effects and underlying mechanisms of ceramide on MMP-9 expression in airway epithelium.

Methods: BEAS-2B cells, normal human bronchial epithelium cell lines, were pretreated with AG490, a selective janus tyrosine kinase 2 (JAK2) inhibitor, or Stattic, a selective signal transducer and activator of transcription 3 (STAT3) inhibitor. The cells were then stimulated with C6-ceramide. The levels of MMP-9 were determined by ELISA and real-time quantitative PCR (RT-qPCR). JAK2, phosphorylated JAK2 ( $p$-JAK2), STAT3, and phosphorylated STAT3 ( $p$ STAT3) expression was examined by Western blotting. BALB/c mice were pretreated with AG490 or Stattic before intratracheally instillated with C6-ceramide. Pathological changes in lung tissues were examined by Hematoxylin and Eosin staining, Periodic-acid Schiff staining, and Masson's trichrome staining. MMP-9, JAK2, p-JAK2, STAT3, and p-STAT3 expression in the lung tissues was examined by Western blotting.

Results: The expression of MMP-9, p-JAK2 and p-STAT3 in BEAS-2B cells was significantly increased after the treatment of C6-ceramide. Furthermore, the increased expression of MMP-9 induced by C6-ceramide was inhibited by AG490 and Stattic. Similar results were obtained in the lung tissues of C6-ceramide-exposed mice which were treated with AG490 or Stattic.

Conclusions: Ceramide could up-regulate MMP-9 expression through the activation of the JAK2/STAT3 pathway in airway epithelium. Targeted modulation of the ceramide signaling pathway may offer a potential therapeutic approach for inhibiting MMP-9 expression. This study points to a potentially novel approach to alleviating airway remodeling in inflammatory airway diseases.
\end{abstract}

Keywords: Ceramide, Airway epithelium, Matrix metalloproteinase 9, Janus tyrosine kinase 2, Signal transducer and activator of transcription 3, Airway remodeling

\footnotetext{
* Correspondence: liulihong@bjcyh.com

'Department of Pharmacy, Beijing Chao-Yang Hospital, Capital Medical University, Beijing, China

Full list of author information is available at the end of the article
}

(c) The Author(s). 2020 Open Access This article is licensed under a Creative Commons Attribution 4.0 International License, which permits use, sharing, adaptation, distribution and reproduction in any medium or format, as long as you give appropriate credit to the original author(s) and the source, provide a link to the Creative Commons licence, and indicate if changes were made. The images or other third party material in this article are included in the article's Creative Commons licence, unless indicated otherwise in a credit line to the material. If material is not included in the article's Creative Commons licence and your intended use is not permitted by statutory regulation or exceeds the permitted use, you will need to obtain permission directly from the copyright holder. To view a copy of this licence, visit http://creativecommons.org/licenses/by/4.0/ The Creative Commons Public Domain Dedication waiver (http://creativecommons.org/publicdomain/zero/1.0/) applies to the data made available in this article, unless otherwise stated in a credit line to the data. 


\section{Introduction}

Airway epithelium is a pivotal structure with the greatest surface exposed to a large number of external stimulus, including respiratory viruses, air pollutants, and allergens. The airway epithelium also plays a significant role in the first line of immunological defense by supporting the activation, recruitment, and mobilization of immune cells [1]. However, growing evidence has showed that pulmonary disorders, such as asthma, chronic obstructive pulmonary disease (COPD), and emphysema, are associated with epithelial dysfunction [2-5]. Dysfunctional airway epithelium synthesizes and releases a variety of potent pro-inflammatory mediators such as nitric oxide, chemokine, and cytokines $[6,7]$. Moreover, epithelium is believed to participate in airway remodeling through aberrant production of extracellular matrix (ECM), chemokines, growth factors, and matrix metalloproteinases (MMPs) [8, 9].

Ceramide, a bioactive lipid, has been implicated in a variety of physiological and pathological processes, such as cell proliferation, differentiation, apoptosis, and inflammation [10, 11]. Various reports have demonstrated the accumulation of ceramide in prevalent lung diseases, such as asthma, acute lung injury, and COPD [12, 13]. Ceramide is significantly increased in the lungs and serum of patients with asthma and COPD [14, 15]. Ceramide is also associated with the phenotypes of asthma and COPD, and may contribute to exacerbation and poor disease control by worsening airway inflammation $[16,17]$. Studies by Oyeniran et al. showed that intratracheal delivery of ceramide in mice promoted pulmonary inflammation and tissue remodeling, and caused airway flow obstruction [18]. In addition, de novo ceramide synthesis contributes to murine lung emphysema development. Ceramide production is markedly increased in the lungs of patients with cigarette smoke-induced emphysema [19]. For the human lung epithelium, an unusual lipid class distribution was found, and ceramide was the predominant sphingolipid [20].

Matrix metalloproteinase 9 (MMP-9), an important enzyme regulating the synthesis and degradation of ECM, is associated with airway remodeling and lung injury in asthma and COPD. MMP-9 directly degrades ECM proteins and is central in facilitating the trafficking of inflammatory cells from the parenchyma to the airways during inflammation [21]. Ceramide metabolism has been linked to MMP-9 expression. Myriocin, a de novo ceramide synthesis inhibitor, showed antioxidant activity and could attenuate MMP-9 expression in cigarette smoke mixture treated human airway epithelium [22]. Buisson-Legendre et al. suggested that ceramide could enhance MMP-9 production in psoriatic keratinocytes [23]. However, the direct effects and mechanisms of ceramide on MMP-9 expression in airway epithelium are not reported.
The objective of this study was therefore to investigate whether ceramide could stimulate MMP-9 expression in airway epithelium. We also aimed to determine the mechanisms of ceramide on MMP-9 expression.

\section{Materials and methods}

Materials

BEAS-2B cell lines were acquired from the American Type Culture Collection (ATCC, Rockville, MA, USA). C6ceramide, ammonium pyrrolidinedithiocarbamate (PDTC), tyrphostin B42 (AG490), and 6-Nitrobenzo[b]thiophene-1, 1dioxide (Stattic) were acquired from Sigma-Aldrich (St Louis, MO, USA). Dulbecco's Modified Eagle's Medium (DMEM) and Fetal bovine serum (FBS) were obtained from HyClone (Logan, UT, USA). Anti-JAK2, anti-phosphorylated JAK2 (pJAK2), anti-STAT3, anti-phosphorylated STAT3 (p-STAT3), anti-CD68, and anti- $\beta$-actin antibodies were acquired from Cell Signaling Technology (Beverly, MA, USA). IRDye 680RD Goat anti-Rabbit and Goat anti-Mouse IgG $(\mathrm{H}+\mathrm{L})$ was acquired from LI-COR Biosciences (Lincoln, NE, USA). TRIzol was acquired from Invitrogen Corporation (Carlsbad, California, USA). TB Green Mixture was acquired from TaKaRa (Otsu, Shiga, Japan).

\section{Cell viability assay}

Cell viability was determined by the Cell Counting Kit-8 (CCK8) assay. BEAS-2B cells were seeded at a density of $1 \times 10^{4}$ cells/well in 96-well plates and cultured overnight. BEAS-2B cells were then treated with AG490 at 20, 10, 5, or $2.5 \mu \mathrm{M}$ or Stattic at $2,1,0.5$, or $0.25 \mu \mathrm{M}$ for $24 \mathrm{~h}$. We added $0.1 \%$ DMSO to control wells. The media was then changed to fresh media, and $10 \mu \mathrm{L}$ of CCK8 solution was added per well. The optical densities (OD) at $450 \mathrm{~nm}$ were measured $4 \mathrm{~h}$ later using a microplate reader (BioTek, Winooski, VT, USA). Cell viabilities were expressed as percentage of controls cultured with 0.1\% DMSO.

\section{Quantification of MMP-9 in BEAS-2B cells}

BEAS-2B cells were seeded at a density of $3 \times 10^{5}$ cells/ well in 6-well plates and cultured overnight. BEAS-2B cells were treated with C6-ceramide $(10,5$, or $2.5 \mu \mathrm{M})$ for $24 \mathrm{~h}$ in serum-free media. DMSO $(0.1 \%)$ was added to control wells. In the experiments involving AG490 and Stattic, AG490 $(10,5$, or $2.5 \mu \mathrm{M})$ and Stattic $(1,0.5$, or $0.25 \mu \mathrm{M})$ were added to the cultures $2 \mathrm{~h}$ prior to the addition of C6-ceramide. First-strand cDNAs were synthesized using Prime Script RT Reagent kit (Takara Bio, Otsu, Japan). Real-time quantitative PCR (RT-qPCR) was performed using TB Green Mixture (Takara Bio, Otsu, Japan). The primer sequences were as follows: human MMP-9, forward: 5'-GATCATTCCTCAGTGCCGGA-3', reverse: 5' -TTCAGGGCGAGGACCATAGA-3'; human GAPDH, forward: 5' -CCACATCGCTCAGACACCAT 3', reverse: 5' - TTGACGGTGCCATGGAATTT-3'. The 
relative mRNA levels of MMP-9 were determined with GAPDH as control and were represented as $2^{-\Delta \Delta \mathrm{Ct}}$. MMP9 protein levels in cell culture supernatant were determined by ELISA (eBioscience, San Diego, CA, USA).

\section{Quantification of JAK2, p-JAK2, STAT3, and p-STAT3 expression in BEAS-2B}

BEAS-2B cells were seeded at a density of $3 \times 10^{5}$ cells/ well in 6-well plates and incubated overnight. Then the cells were treated with C6-ceramide $(10,5$, or $2.5 \mu \mathrm{M})$ for $24 \mathrm{~h}$ in serum-free media. DMSO $(0.1 \%)$ was added to control wells. JAK2, p-JAK2, STAT3, and p-STAT3 levels were examined by Western blotting. Band density was quantified by QuantiScan Version 11 (Biosoft, Cambridge, UK).

\section{Animal studies}

Specifc pathogen free male $\mathrm{BALB} / \mathrm{c}$ mice $(18-20 \mathrm{~g}$, Beijing HFK Bioscience Co, Ltd., Beijing, China) were randomly divided into 4 groups $(n=6)$ : the naive normal control group was exposed to vehicle control; the C6ceramide group was exposed to C6-ceramide and pretreated with 5\% DMSO; the AG490 group was exposed to C6-ceramide and was pretreated with AG490 (15 mg/ kg i.p., dissolved in 5\% DMSO); and the Stattic group was exposed to C6-ceramide and was pretreated with Stattic ( $5 \mathrm{mg} / \mathrm{kg}$ i.p., dissolved in 5\% DMSO). These animals were exposed to C6-ceramide at $5 \mathrm{mg} / \mathrm{kg}$ of body weight or vehicle control by intratracheal instillation for 3 days. One hour before C6-ceramide exposure on each day, the animals were intraperitoneally injected with AG490, Stattic, or 5\% DMSO as indicated above. The lung tissues were then fixed with $4 \%$ buffered formalin solution. Pathological changes in the lung tissues were examined using Hematoxylin and Eosin (H\&E) staining, Periodic Acid-Schiff (PAS) staining, and Masson's trichrome staining. CD68 staining was conducted by immunohistochemistry. MMP-9, JAK2, p-JAK2, STAT3, and p-STAT3 levels in lung tissues were examined by Western blotting.

\section{Statistical analysis}

Data were expressed as the mean $\pm \mathrm{SD}$ or as median with range from three independent experiments. T-test was used to compare means between two groups. Oneway ANOVA followed by Tukey post hoc test was used to compare means between three or more groups. Nonparametric data were analyzed using the Kruskal-Wallis test and results were presented as the median and interquartile range. A $P$ value of 0.05 or lower was considered statistically significant.

\section{Results}

C6-ceramide increased MMP-9 expression in BEAS-2B

In order to study the effects of ceramide on MMP-9 expression, human bronchial epithelial BEAS-2B cells were treated with C6-ceramide, a synthetic cell-permeable ceramide analog. The effects of C6-ceramide on MMP-9 expression were determined by RT-qPCR and ELISA, as described in the experimental procedures.

Compared to cells incubated with DMSO only, treatment with $10 \mu \mathrm{M}, 5 \mu \mathrm{M}$, and $2.5 \mu \mathrm{M}$ of C6-ceramide increased the relative MMP-9 mRNA levels from $1.00 \pm$ 0.09 to $6.62 \pm 0.65(P<0.01), 4.68 \pm 0.32(P<0.01)$, and $3.82 \pm 0.15(P<0.01)$, respectively (Fig. 1a), and increased the MMP-9 protein levels from $387.57 \pm 40.79$ $\mathrm{pg} / \mathrm{mL}$ to $4481.76 \pm 506.40 \mathrm{pg} / \mathrm{mL}(P<0.01), 3361.10 \pm$ $139.19 \mathrm{pg} / \mathrm{mL} \quad(P<0.01)$, and $1536.25 \pm 53.05 \mathrm{pg} / \mathrm{mL}$ $(P<0.01)$, respectively (Fig. 1b). These data suggested that MMP-9 expression was increased by C6-ceramide in human bronchial epithelial cell line BEAS-2B.

\section{Inhibition of JAK2 and STAT3 reduced MMP-9 expression in C6-ceramide-treated BEAS-2B}

Ceramide has been reported to induce the activation of various inflammatory signaling pathways, including JAK2/STAT3 and NF-kB [24-26]. Therefore, the involvement of the JAK2/STAT3 and NF-kB pathway in ceramide-induced MMP-9 expression was examined in this study. The cell viability was not significantly affected when BEAS-2B cells were exposed to AG490 (10, 5, or $2.5 \mu \mathrm{M})$ and Stattic $(1,0.5$, or $0.25 \mu \mathrm{M})$ for $24 \mathrm{~h}$ (Fig. $2 \mathrm{a}$ and b). However, $20 \mu \mathrm{M}$ of AG490 and $2 \mu \mathrm{M}$ of Stattic reduced the cell viability of BEAS-2B cells to $55.87 \%$ (range 53.74-56.95\%) $\quad(P=0.04)$ and $76.10 \%$ (range 76.19-82.40\%) of control $(P=0.01)$ (Fig. $2 \mathrm{a}$ and b), respectively. Therefore, AG490 $(10,5$, or $2.5 \mu \mathrm{M})$ and Stattic $(1,0.5$, or $0.25 \mu \mathrm{M})$ were selected for this study.

BEAS-2B cells were pretreated with signal pathway inhibitors, such as PDTC (NF-kB inhibitor), AG490 (JAK2 inhibitor), and Stattic (STAT3 inhibitor), for $2 \mathrm{~h}$ before being incubated with $10 \mu \mathrm{M}$ of C6-ceramide for $24 \mathrm{~h}$. MMP-9 levels were determined by RT-qPCR and ELISA. Compared to the cells incubated with C6-ceramide only, pretreatment with $10 \mu \mathrm{M}, 5 \mu \mathrm{M}$, and $2.5 \mu \mathrm{M}$ of AG490 decreased the relative MMP-9 mRNA levels from $4.52 \pm$ 0.59 to $1.69 \pm 0.05(P<0.01), 2.21 \pm 0.12(P<0.01)$, and $3.17 \pm 0.67(P<0.01)$, respectively (Fig. 2 c), and decreased the MMP-9 protein levels from $4689.59 \pm$ $335.46 \mathrm{pg} / \mathrm{mL}$ to $2010.22 \pm 146.44 \mathrm{pg} / \mathrm{mL} \quad(P<0.01)$, $2553.77 \pm 111.76 \mathrm{pg} / \mathrm{mL}(P<0.01)$, and $3674.43 \pm 448.99$ $\mathrm{pg} / \mathrm{mL}(P<0.01)$, respectively (Fig. $2 \mathrm{~d})$. In addition, combination treatment of BEAS-2B cells with $10 \mu \mathrm{M}$ of AG490 and $1 \mu \mathrm{M}$ of Stattic decreased the mRNA and protein level of MMP-9 to $1.64 \pm 0.20(P<0.01)$ and $1997.43 \pm 38.07 \mathrm{pg} / \mathrm{mL}(P<0.01)$, respectively, similar to 

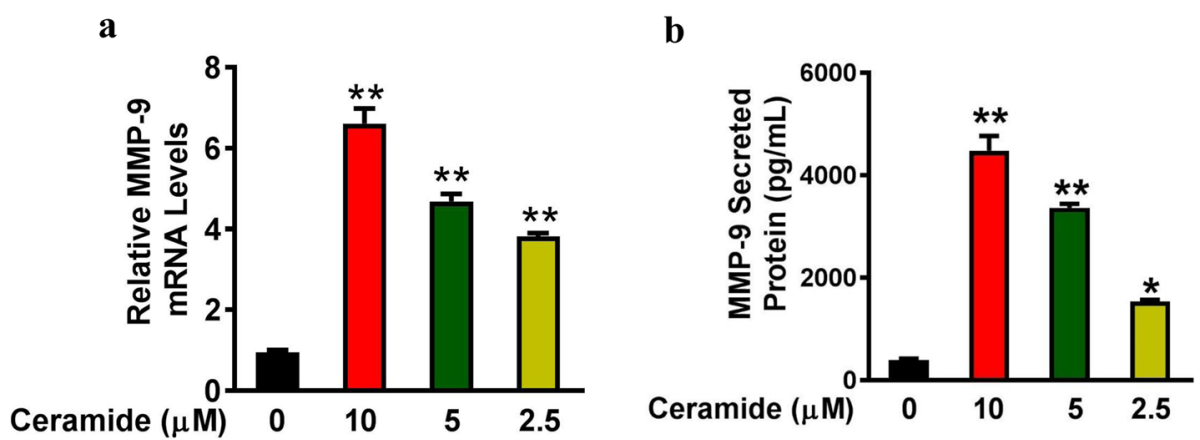

Fig. 1 BEAS-2B cells were treated with C6-ceramide $(10 \mu \mathrm{M}, 5 \mu \mathrm{M}$, or $2.5 \mu \mathrm{M})$ or $0.1 \%$ DMSO (vehicle) for $24 \mathrm{~h}$. The MMP-9 levels were determined by RT-qPCR (a) and ELISA (b). $n=3$ per group. ${ }^{*} P<0.05,{ }^{* *} P<0.01$ vs controls that were treated with $0.1 \%$ DMSO

the effect of $10 \mu \mathrm{M}$ AG490. Meanwhile, when the cells were pretreated with $1 \mu \mathrm{M}, 0.5 \mu \mathrm{M}$, and $0.25 \mu \mathrm{M}$ of Stattic for $2 \mathrm{~h}$, the relative MMP-9 mRNA levels decreased from $4.75 \pm 0.05$ to $2.00 \pm 0.02(P<0.01), 2.94 \pm 0.08$ $(P<0.01)$, and $3.59 \pm 0.06(P<0.01)$, respectively (Fig. $2 \mathrm{e})$, and the MMP-9 protein levels decreased from $4689.59 \pm 335.46 \mathrm{pg} / \mathrm{mL}$ to $1962.26 \pm 223.53 \mathrm{pg} / \mathrm{mL}(P<$
$0.01), 2879.90 \pm 303.29 \mathrm{pg} / \mathrm{mL}(P<0.01)$, and $3194.83 \pm$ $318.90 \mathrm{pg} / \mathrm{mL}(P<0.01)$, respectively (Fig. $2 \mathrm{f})$. Combination treatment of BEAS-2B cells with Stattic $(1 \mu \mathrm{M})$ and AG490 $(10 \mu \mathrm{M})$ decreased the mRNA and protein level of MMP-9 to $2.11 \pm 0.31(P<0.01)$ and $1997.43 \pm$ $38.07 \mathrm{pg} / \mathrm{mL}(P<0.01)$, respectively, similar to the effect of $1 \mu \mathrm{M}$ Stattic. Meanwhile, AG490 and Stattic did not

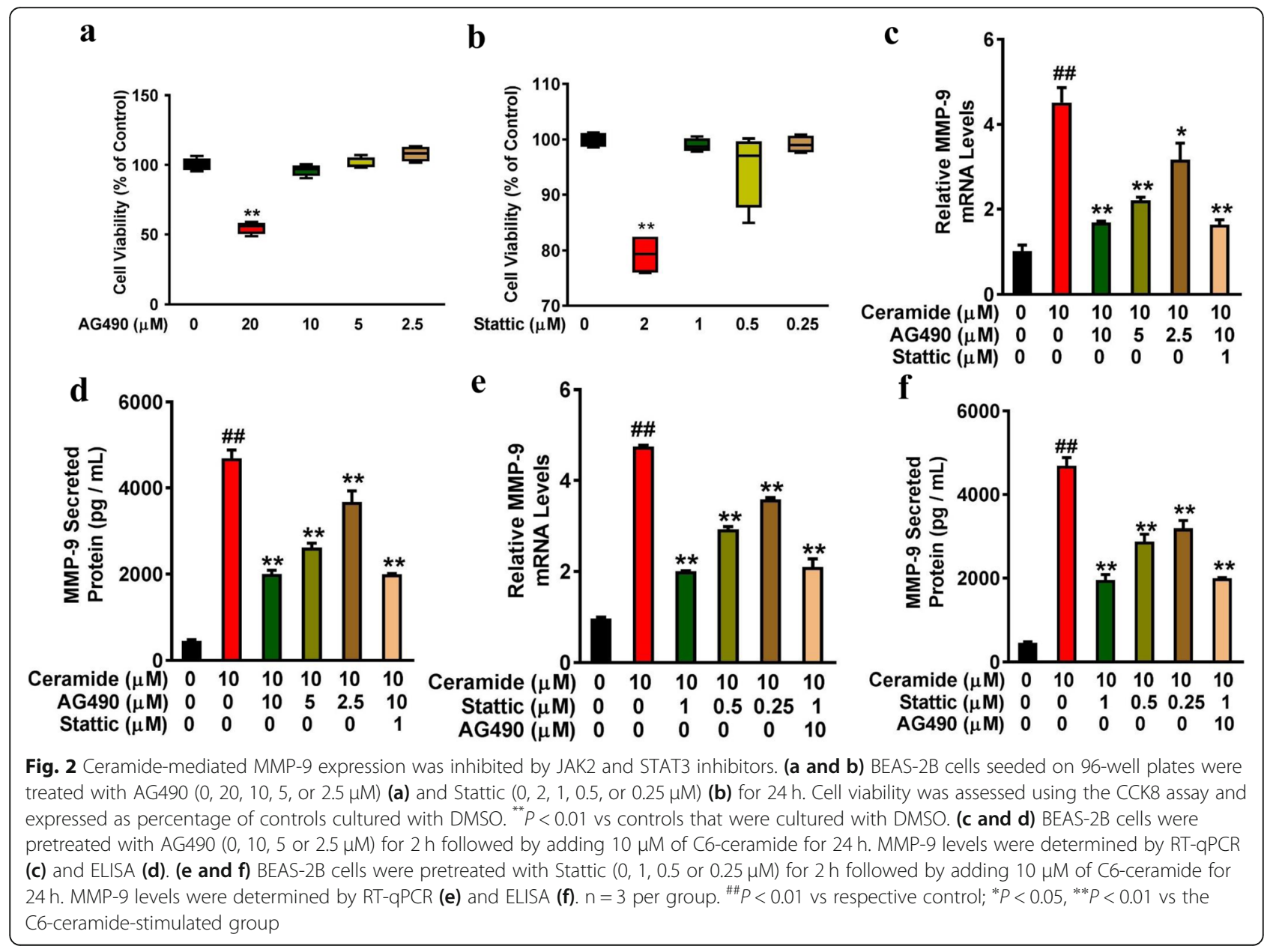


affect the expression of MMP-9 in the absence C6ceramide (Fig. S1). Treatment with PDTC, the NF-kB inhibitor, had no significant effect on MMP-9 expression (data not shown). These results suggested that the JAK2/STAT3 signaling pathway may be involved in ceramide-induced MMP-9 expression.

\section{C6-ceramide induced phosphorylation of JAK2 and STAT3 in BEAS-2B}

To confirm these results, the p-JAK2 and p-STAT3 levels were examined. As shown in Fig. 3a, treatment with $10 \mu \mathrm{M}$, $5 \mu \mathrm{M}$, and $2.5 \mu \mathrm{M}$ of C6-ceramide increased relative p-JAK2/ JAK2 expression from $0.56 \pm 0.06$ to $0.85 \pm 0.05(P=0.02)$, $0.79 \pm 0.05(P=0.04)$, and $0.75 \pm 0.08(P=0.05)$, respectively (Fig. 3a). In a similar pattern, treatment with $10 \mu \mathrm{M}, 5 \mu \mathrm{M}$, and $2.5 \mu \mathrm{M}$ of C6-ceramide increased p-STAT3/STAT3 expression from $0.33 \pm 0.02$ to $0.72 \pm 0.03(P<0.01), 0.68 \pm 0.04$ $(P<0.01)$, and $0.64 \pm 0.02(P<0.01)$, respectively (Fig. $3 \mathrm{~b})$.

\section{Intratracheal instillation of ceramide increased while AG490 and Stattic administration attenuated MMP-9 expression in vivo}

To further investigate the effect and mechanism of ceramide on MMP-9 expression, BALB/c mice were pretreated with AG490 at $15 \mathrm{mg} / \mathrm{kg}$ of body weight or Stattic at $5 \mathrm{mg} / \mathrm{kg}$ of body weight. BALB/c mice were then exposed to $5 \mathrm{mg} / \mathrm{kg}$ of C6-ceramide by intratracheal instillation. C6-ceramide induced a severe inflammatory reaction, characterized by inflammatory cell infiltration, desquamation of bronchial epithelium (Fig. 4a), and mucus production (Fig. 4b). C6-ceramide also induced a dramatic increase in the extent of collagen deposition (Fig. 4c). To visualize inflammatory cell infiltration, the lung tissues were stained with macrophage marker CD68. A highly significant infiltration of CD68 positive cells was observed in C6-ceramide exposed mice lung tissues (Fig. 4d). AG490 at $15 \mathrm{mg} / \mathrm{kg}$ of body weight and
Stattic at $5 \mathrm{mg} / \mathrm{kg}$ of body weight markedly attenuated the C6-ceramide-induced inflammatory cell infiltration, mucus production and collagen deposition in the lung tissues (Fig. 4a-c). The accumulation of CD68 positive cells was also markedly reduced when treated with AG490 and Stattic (Fig. 4d). MMP-9 levels in the lung tissues were examined by RT-qPCR and Western blotting. The MMP-9 mRNA levels significantly increased to $14.03 \pm 2.92$ in the C6-ceramide-exposed group compared with the vehicle treated mice $(P<0.01)$, while the pretreatment with AG490 and Stattic decreased this level to $3.65 \pm 0.28$ ( $P=$ $0.03)$ and $4.82 \pm 0.26(P=0.02)$, respectively (Fig. 4e). In a similar pattern, the MMP-9 protein levels significantly increased to $0.73 \pm 0.04$ in the C6-ceramide-exposed group compared with the vehicle treated mice $(0.51 \pm 0.03, P<$ 0.01 ), while the pretreatment with AG490 and Stattic decreased this level to $0.60 \pm 0.02(P=0.03)$ and $0.59 \pm 0.07$ $(P=0.02)$, respectively (Fig. $4 \mathrm{f})$.

\section{Direct intratracheal instillation of ceramide induced phosphorylation of JAK2 and STAT3 in vivo}

Consistent with the in vitro studies above, intratracheal instillation of C6-ceramide in BALB/c mice increased relative p-JAK2/JAK2 expression in lung tissues from $0.51 \pm 0.08$ to $0.74 \pm 0.06(p<0.01)$ (Fig. 5a), and increased relative $\mathrm{p}$-STAT3/STAT3 expression from $0.49 \pm 0.02$ to $0.69 \pm 0.15(p<0.01)$ (Fig. $5 b)$. Treatment with AG490 reduced relative p-JAK2/JAK2 expression in lung tissues from $0.74 \pm 0.06$ to $0.62 \pm 0.03(P=0.04)$ (Fig. 5a). In a similar pattern, treatment with AG490 and Stattic reduced relative p-STAT3/STAT3 expression in lung tissues from $0.69 \pm 0.15$ to $0.51 \pm 0.05(P<0.01)$ and $0.56 \pm 0.03(P=0.04)$, respectively (Fig. $5 \mathrm{~b})$.

\section{Discussion}

Increased ceramide level is associated with chronic lung diseases, including asthma, COPD, and emphysema [12,
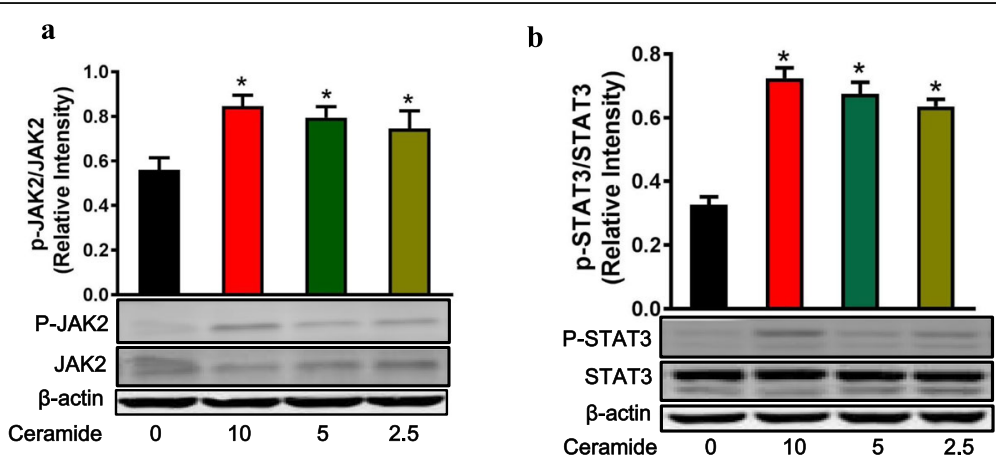

Fig. 3 C6-ceramide induces phosphorylation of JAK2 and STAT3 in BEAS-2B cells. After serum starvation for $24 \mathrm{~h}, \mathrm{BEAS}-2 \mathrm{~B}$ cells were treated with C6-ceramide $(10 \mu \mathrm{M})$ for $24 \mathrm{~h}$. (a) JAK2 and p-JAK2 expression was examined by Western blotting, and relative quantification of the $\mathrm{p}$-JAK2/JAK2 expression was determined by densitometric analysis of the blots. (b) STAT3 and p-STAT3 expression was examined by Western blotting, and relative quantification of the $\mathrm{p}$-STAT3/STAT3 expression was determined by densitometric analysis of the blots. $n=3$ per group. ${ }^{*} P<0.05$ vs controls that were cultured in the absence of C6-ceramide 


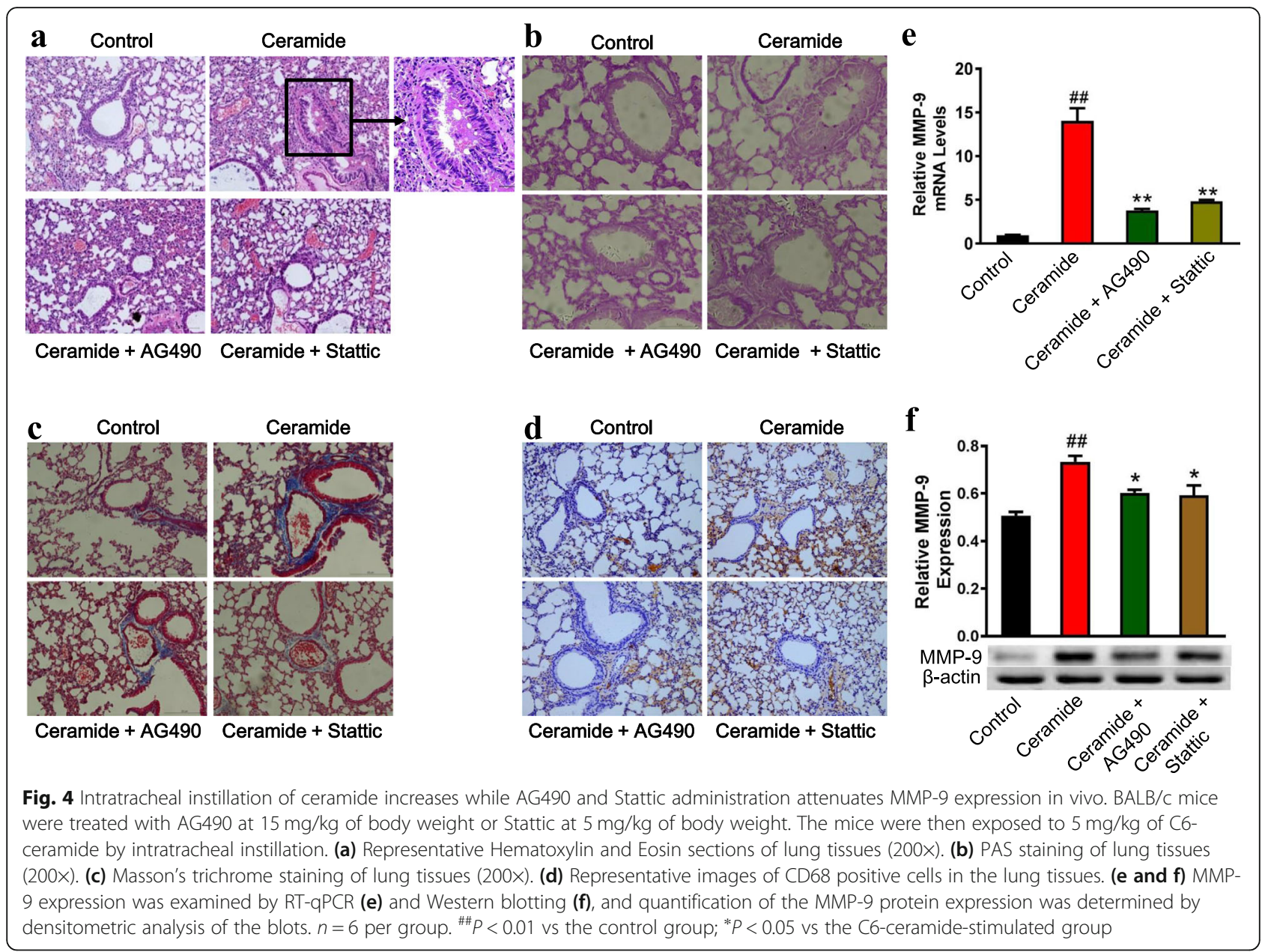

a

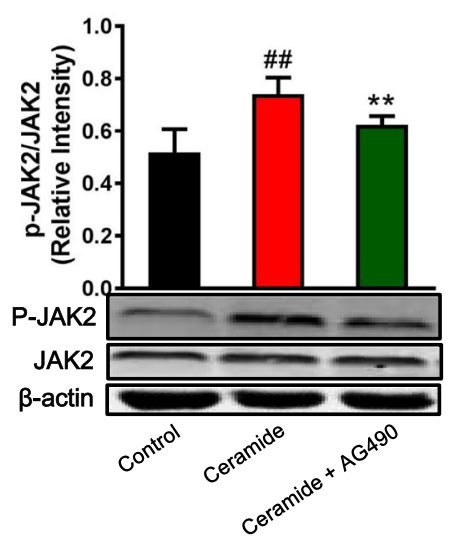

b

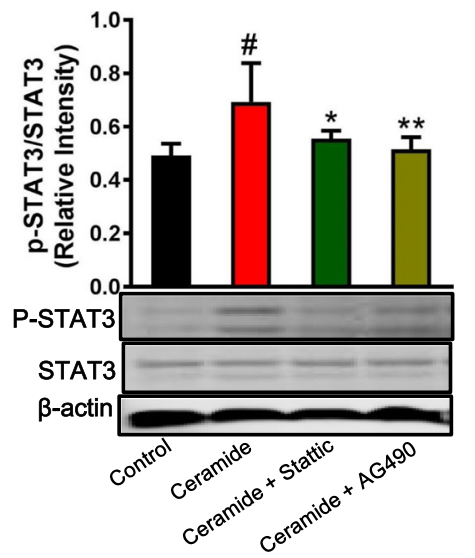

Fig. 5 Direct intratracheal instillation of ceramide induces phosphorylation of JAK2 and STAT3 in vivo. BALB/c mice were treated with AG490 at $15 \mathrm{mg} / \mathrm{kg}$ of body weight or Stattic at $5 \mathrm{mg} / \mathrm{kg}$ of body weight. The mice were then exposed to $5 \mathrm{mg} / \mathrm{kg}$ of C6-ceramide by intratracheal instillation. (a) JAK2 and p-JAK2 expression was examined by Western blotting, and relative quantification of the p-JAK2/JAK2 expression was determined by densitometric analysis of the blots. (b) STAT3 and p-STAT3 expression was examined by Western blotting, and relative quantification of the p-STAT3/STAT3 expression was determined by densitometric analysis of the blots. $\mathrm{n}=6$ per group. ${ }^{\#} P<0.05$, ${ }^{\# \#} P<0.01$ vs the control group; ${ }^{*} P<0.05,{ }^{* *} P<0.05$ vs the C6-ceramide-stimulated group 
13, 19]. Ceramide has attracted much attention for its potential pro-inflammatory, pro-apoptosis, and prooxidant properties [10], while the ceramide-mediated MMP-9 expression in airway epithelium has not been fully studied. This study showed that ceramide promoted MMP-9 production via activation of the JAK2/STAT3 pathway. These data adds ceramide as a novel potent inducer of MMP-9 in the airway epithelium.

MMPs play an essential role in tissue remodeling and they also contribute to excessive breakdown of connective tissue in inflammatory disorders, such as asthma, COPD, and rheumatoid arthritis. MMP-7 and MMP-9 are the predominant forms of MMPs expressed by epithelial cells in lung tissues [27]. MMP-9 degrades elastin, collagen, fibrin, and other extracellular and is central in facilitating the trafficking of inflammatory cells from the parenchyma to the airways during inflammation [21]. Increased level of MMP-9 was found in exhaled breath condensates, bronchoalveolar lavage fluid (BALF), and sputum of patients with asthma and COPD [28]. It is well known that the expression and secretion of MMP-9 in chronic lung diseases is regulated by various stimuli, including IL-1 $\beta$, TNF- $\alpha$, and LPSs. Hozumi et al. reported that TNF- $\alpha$ and IL-1 $\beta$ induced MMP-9 expression in human bronchial epithelial cells via $N F-\kappa B$ activation [29]. In addition, Shan et al. demonstrated that platelet activating factor increased MMP-9 expression in human bronchial epithelial cells [30]. Ceramide, a bioactive lipid, has been implicated in a variety of physiological and pathological processes, such as cell proliferation, differentiation, apoptosis, and inflammation. Studies indicate that changes in the ceramide content of the airway epithelium play an essential role in several pulmonary inflammatory diseases. Firstly, ceramide upregulation induces airway epithelium apoptosis. For example, increased ceramide production was observed in the airway epithelium in an experimental asthma model. Inhibition of de novo ceramide synthesis with the ceramide synthase inhibitor fumonisin B1 attenuated oxidative/nitrosative stress, epithelial cell apoptosis, and airway inflammation, and improved the respiratory and histopathological abnormalities [13]. Filosto et al. showed that augmented ceramide production induced the apoptosis of human bronchial epithelial 1 and adenocarcinomic human alveolar basal epithelial cells (A549), and ceramide generation is upstream of the caspase cascades [31]. In addition, our previous studies demonstrated that Vam3, a resveratrol dimer, attenuated ceramide accumulation and inhibited apoptosis in mouse lungs exposed to cigarette smoke [32]. Secondly, increased ceramide generation triggers oxidative stress. Ceramide was reported to induce oxidative damage by increasing ROS generation or by decreasing ROS elimination [33]. Previous studies suggested that ceramide promoted oxidative stress via generation of superoxide, and contributed to cigarette smoke-induced lung injury [34]. Thirdly, increased ceramide concentration in airway epithelium triggered chronic pulmonary inflammation [35]. These studies indicated that the increased production of ceramides in the airway epithelium played an important role in apoptosis, oxidative stress and inflammation. However, the ceramide-mediated MMP-9 expression in airway epithelium has not been fully studied. In this study, the mRNA levels of MMP-9 and MMP-7 were determined in BEAS-2B cells using RTqPCR. Ceramide did not affect the mRNA levels of MMP-7 (data not shown). However, ceramide was a novel potent inducer of MMP-9 in airway epithelium. C6-ceramide significantly increased MMP-9 expression in BEAS-2B cells. Direct intratracheal instillation of ceramide induced MMP-9 expression in mouse lungs, and promoted inflammatory cells infiltration, mucus production and collagen deposition.

Ceramide could induce the activation of various inflammatory signaling pathways, including NLRP3/Caspase1/IL-1 $\beta$, JAK/STAT and NF-kB [24-26, 36]. Grassmé et al. showed the activation of the NLRP3 inflammasome by the increased ceramide levels in Cystic Fibrosis airways [37]. The ceramide-induced activation of NF- $\mathrm{kB}$ promotes the production of several inflammatory mediators and adhesion molecules [26]. Kim et al. reported that ceramide up-regulated MMP-1 expression via activation of JAK1/STAT-1 pathway in human dermal fibroblasts [25], while Reunanen et al. reported that enhancement of MMP-1 gene expression by ceramide was mediated via extracellular signal-regulated and stress-activated protein kinase pathways [38]. In preliminary experiment, C6-ceramide treatment activated phosphorylation of JAK1 and JAK2 in airway epithelium. Meanwhile, C6-ceramide stimulated the phosphorylation of JAK2 to a significantly larger extent than JAK1 in BEAS-2B cells (data not shown). C6-ceramide-induced MMP-9 expression was significantly decreased by JAK2 inhibitor AG490 but not by NF-kB inhibitor PDTC. Once activated, JAK2 initiates a number of downstream molecules, including STAT3 and STAT5. STAT3 is a key player in epithelial cell migration and is required for repair of the bronchiolar epithelium [39]. Moreover, activation of STAT3 adjusts and controls MMP-9 expression $[27,40]$. This study showed that p-STAT3 levels were remarkably elevated in ceramide treated BEAS-2B cells and mice lungs. Static, the selective STAT3 inhibitor, was used to verify the involvement of STAT3 in MMP-9 expression. The results demonstrated that C6ceramide-induced MMP-9 expression was significantly decreased by Stattic. Consistent with the in vitro studies above, direct intratracheal instillation of ceramide induced a significant increase in MMP-9 expression in the 
lungs, and caused significant pulmonary inflammation, mucus hypersecretion, and collagen deposition which can be seen in the histopathological data. Administration of AG490 and Stattic reduced the levels of p-JAK2 and p-STAT3, and ameliorated MMP-9 expression and airway remodeling. Meanwhile, AG490 and Stattic ameliorated ceramide-induced pathologic changes, including mucus hypersecretion and collagen deposition. JAK2/ STAT3 is an important signaling pathway to regulate multiple gene expression, including MMP-9. This study demonstrated that C6-ceramide treatment significantly activated the JAK2/STAT3 signaling. C6-ceramide mediated MMP-9 expression was inhibited by JAK2/STST3 signaling inhibitors (AG490 and Stattic). However, C6ceramide did not affect the expression of MMP-9 in the absence C6-ceramide.

\section{Study strengths and limitations}

The strengths of this study were listed as following: First, the study reported the effect of ceramide on MMP-9 production in airway epithelium which has not been reported. Second, this study clarify the pathway involved in ceramide-induced MMP-9 expression in airway epithelium. Some limitations of the study deserve to be mentioned. Firstly, JAK2 knock-out mice and STAT3 knockout mice are needed to confirm these results. Secondly, MMP-9 expression was only partly inhibited by AG490 and Stattic. In airway epithelium, other signaling pathway may be involved in ceramide-induced MMP-9 expresison. Thus, further studies are needed to investigate the involvement of other signaling pathway in ceramide-induced MMP-9 expression in airway epithelium.

\section{Conclusions}

In conclusion, the findings of the present study suggest that ceramide may induce MMP-9 expression in airway epithelium via the JAK2/STAT3 pathway. Therefore, targeted modulation of the ceramide signaling pathway may offer a potential therapeutic approach for inhibiting MMP-9 expression in airway epithelium. Further understanding of the mechanisms responsible for pathological remodeling may highlight novel therapeutic strategies in chronic inflammatory airway disease, such as asthma and COPD.

\section{Supplementary information}

Supplementary information accompanies this paper at https://doi.org/10. 1186/s12944-020-01373-w.

\section{Additional file 1: Figure S1.}

\section{Abbreviations}

BALF: Bronchoalveolar Lavage Fluid; COPD: Chronic Obstructive Pulmonary Disease; DMEM: Dulbecco's Modified Eagle's Medium; ECM: Extracellular Matrix; FBS: Fetal Bovine Serum; JAK2: Janus Tyrosine Kinase 2; MMPs: Matrix
Metalloproteinases; MMP-9: Matrix Metallopeptidase 9; RT-qPCR: Real-Time Quantitative PCR; STAT3: Signal Transducer and Activator of Transcription 3

Acknowledgements

Not applicable.

\section{Authors' contributions}

Lingling Xuan designed and performed the experiments, analyzed the data, and drafted the manuscript. Feifei Han and Lili Gong helped in in vitro experiments. Yali Lv and Zirui Wan helped in animal experiments. He Liu provided assistance in the experiment design. Lulu Ren, Song Yang, and Wen Zhang helped in the analysis of data. Chunting Tan revised the manuscript. Lihong Liu designed the study, drafted and revised the manuscript. All authors read and approved the final manuscript.

\section{Funding}

This study was supported by the National Natural Science Foundation of China (81903692), Wu Jieping Medical Foundation (320.6750.2020-04-19), and Scientific Research Foundation of Capital Medical University (NO.

PYZ2018030 and 3500-1182080843).

Availability of data and materials

Data are available from the authors on request.

Ethics approval and consent to participate

The animal studies followed the instructions of the Laboratory Animal Management Statute of China Physiological Society. All the animal experiments were approved by the Beijing Chao-Yang Hospital Committee on Ethics in the Care and Use of Laboratory Animals. The number for ethical approval was 2018-2-7-26.

Consent for publication

Not applicable.

\section{Competing interests}

The authors declare that they have no competing interests.

\section{Author details}

${ }^{1}$ Department of Pharmacy, Beijing Chao-Yang Hospital, Capital Medical University, Beijing, China. ${ }^{2}$ Department of Geriatrics, Affiliated Brain Hospital of Nanjing Medical University, Nanjing, China. ${ }^{3}$ Department of Respiratory Medicine, Beijing Friendship Hospital, Capital Medical University, Beijing, China.

Received: 22 March 2020 Accepted: 17 August 2020

Published online: 24 August 2020

\section{References}

1. Lopez-Rodriguez JC, Benede S, Barderas R, Villalba M, Batanero E. Airway epithelium plays a leading role in the complex framework underlying respiratory allergy. J Investig Allergol Clin Immunol. 2017;27(6):346-55.

2. Gon $Y$, Hashimoto S. Role of airway epithelial barrier dysfunction in pathogenesis of asthma. Allergol Int. 2018;67(1):12-7.

3. Liu Q, Li H, Wang Q, Zhang Y, Wang W, Dou S, Xiao W. Increased expression of TROP2 in airway basal cells potentially contributes to airway remodeling in chronic obstructive pulmonary disease. Respir Res. 2016;17(1):159.

4. Liu H, Hua L, Liu Q, Pan J, Bao Y. Cold stimuli facilitate inflammatory responses through transient receptor potential Melastatin 8 (TRPM8) in primary airway epithelial cells of asthmatic mice. Inflammation. 2018;41(4): 1266-75.

5. Potaczek DP, Miethe S, Schindler V, Alhamdan F, Garn H. Role of airway epithelial cells in the development of different asthma phenotypes. Cell Signal. 2020;69:109523.

6. Nadeem A, Al-Harbi NO, Ahmad SF, Ibrahim KE, Alotaibi MR, Siddiqui N, Alsharari SD, Attia SM, Al-Harbi MM. Protease activated receptor-2 mediated upregulation of $\mathrm{IL}-17$ receptor signaling on airway epithelial cells is responsible for neutrophilic infiltration during acute exposure of house dust mite allergens in mice. Chem Biol Interact. 2019;304:52-60.

7. Gandhi VD, Vliagoftis $\mathrm{H}$. Airway epithelium interactions with aeroallergens: role of secreted cytokines and chemokines in innate immunity. Front Immunol. 2015;6:147. 
8. Royer PJ, Henrio K, Pain M, Loy J, Roux A, Tissot A, Lacoste P, Pison C, Brouard S, Magnan A. TLR3 promotes MMP-9 production in primary human airway epithelial cells through Wnt/beta-catenin signaling. Respir Res. 2017; 18(1):208.

9. Wight TN, Frevert CW, Debley JS, Reeves SR, Parks WC, Ziegler SF. Interplay of extracellular matrix and leukocytes in lung inflammation. Cell Immunol. 2017;312:1-14

10. Pagadala M, Kasumov T, McCullough AJ, Zein NN, Kirwan JP. Role of ceramides in nonalcoholic fatty liver disease. Trends Endocrinol Metab. 2012;23(8):365-71.

11. Yang RX, Pan Q, Liu XL, Zhou D, Xin FZ, Zhao ZH, Zhang RN, Zeng J, Qiao L, $\mathrm{Hu} C X$, et al. Therapeutic effect and autophagy regulation of myriocin in nonalcoholic steatohepatitis. Lipids Health Dis. 2019;18(1):179.

12. Petrache I, Kamocki K, Poirier C, Pewzner-Jung Y, Laviad EL, Schweitzer KS, Van Demark M, Justice MJ, Hubbard WC, Futerman AH. Ceramide synthases expression and role of ceramide synthase-2 in the lung: insight from human lung cells and mouse models. PLoS One. 2013;8(5):e62968.

13. Masini E, Giannini L, Nistri S, Cinci L, Mastroianni R, Xu W, Comhair SA, Li D, Cuzzocrea S, Matuschak GM, Salvemini D. Ceramide: a key signaling molecule in a Guinea pig model of allergic asthmatic response and airway inflammation. J Pharmacol Exp Ther. 2008:324(2):548-57.

14. Lea SR, Metcalfe HJ, Plumb J, Beerli C, Poll C, Singh D, Abbott-Banner KH. Neutral sphingomyelinase-2, acid sphingomyelinase, and ceramide levels in COPD patients compared to controls. Int J Chron Obstruct Pulmon Dis. 2016;11:2139-47.

15. Yang Y, Uhlig $S$. The role of sphingolipids in respiratory disease. Ther Adv Respir Dis. 2011;5(5):325-44.

16. Bowler RP, Jacobson S, Cruickshank C, Hughes GJ, Siska C, Ory DS, Petrache I, Schaffer JE, Reisdorph N, Kechris K. Plasma sphingolipids associated with chronic obstructive pulmonary disease phenotypes. Am J Respir Crit Care Med. 2015;191(3):275-84.

17. Kim SH, Jung HW, Kim M, Moon JY, Ban GY, Kim SJ, Yoo HJ, Park HS. Ceramide/ sphingosine-1-phosphate imbalance is associated with distinct inflammatory phenotypes of uncontrolled asthma. Allergy. 2020;75(8):1987-2000.

18. Oyeniran C, Sturgill JL, Hait NC, Huang WC, Avni D, Maceyka M, Newton J, Allegood JC, Montpetit A, Conrad DH, et al: Aberrant ORM (yeast)-like protein isoform 3 (ORMDL3) expression dysregulates ceramide homeostasis in cells and ceramide exacerbates allergic asthma in mice. J Allergy Clin Immunol. 2015; 136(4):1035-46.e6.

19. Petrache I, Natarajan V, Zhen L, Medler TR, Richter AT, Cho C, Hubbard WC, Berdyshev EV, Tuder RM. Ceramide upregulation causes pulmonary cell apoptosis and emphysema-like disease in mice. Nat Med. 2005;11(5):491-8.

20. Zehethofer N, Bermbach S, Hagner S, Garn H, Muller J, Goldmann T, Lindner B, Schwudke D, Konig P. Lipid analysis of airway epithelial cells for studying respiratory diseases. Chromatographia. 2015;78(5-6):403-13.

21. Bruun CS, Leifsson PS, Johansen LK, Jensen HE, Nielsen J, Fredholm M. Expression of matrix metalloproteinase- 9 and -12 in porcine lung infections. J Comp Pathol. 2012;146(2-3):253-7.

22. Zulueta A, Caretti A, Campisi GM, Brizzolari A, Abad JL, Paroni R, Signorelli P, Ghidoni R. Inhibitors of ceramide de novo biosynthesis rescue damages induced by cigarette smoke in airways epithelia. Naunyn Schmiedeberg's Arch Pharmacol. 2017;390(7):753-9.

23. Buisson-Legendre N, Emonard H, Bernard P, Hornebeck W. Relationship between cell-associated matrix metalloproteinase 9 and psoriatic keratinocyte growth. J Invest Dermatol. 2000;115(2):213-8.

24. Vandanmagsar B, Youm YH, Ravussin A, Galgani JE, Stadler K, Mynatt RL, Ravussin E, Stephens JM, Dixit VD. The NLRP3 inflammasome instigates obesityinduced inflammation and insulin resistance. Nat Med. 2011;17(2):179-88.

25. Kim S, Kim Y, Lee Y, Chung JH. Ceramide accelerates ultraviolet-induced MMP-1 expression through JAK1/STAT-1 pathway in cultured human dermal fibroblasts. J Lipid Res. 2008;49(12):2571-81.

26. Won JS, Im YB, Khan M, Singh AK, Singh I. The role of neutral sphingomyelinase produced ceramide in lipopolysaccharide-mediated expression of inducible nitric oxide synthase. J Neurochem. 2004;88(3):583-93.

27. Crosby LM, Waters CM. Epithelial repair mechanisms in the lung. Am J Physiol Lung Cell Mol Physiol. 2010;298(6):L715-31.

28. Dragicevic S, Kosnik M, Divac Rankov A, Rijavec M, Milosevic K, Korosec P, Skerbinjek Kavalar M, Nikolic A. The variants in the 3' Untranslated region of the matrix metalloproteinase 9 gene as modulators of treatment outcome in children with asthma. Lung. 2018;196(3):297-303.
29. Hozumi A, Nishimura Y, Nishiuma T, Kotani Y, Yokoyama M. Induction of MMP-9 in normal human bronchial epithelial cells by TNF-alpha via NFkappa B-mediated pathway. Am J Physiol Lung Cell Mol Physiol. 2001; 281(6):L1444-52.

30. Shan L, Nishimura Y, Kotani Y, Yokoyama M. Platelet-activating factor increases the expression of metalloproteinase-9 in human bronchial epithelial cells. Eur J Pharmacol. 1999;374(1):147-56.

31. Filosto S, Castillo S, Danielson A, Franzi L, Khan E, Kenyon N, Last J, Pinkerton K, Tuder R, Goldkorn T. Neutral sphingomyelinase 2: a novel target in cigarette smoke-induced apoptosis and lung injury. Am J Respir Cell Mol Biol. 2011:44(3):350-60.

32. Xuan LL, Shi J, Yao CS, Bai JY, Qu F, Zhang JL, Hou Q. Vam3, a resveratrol dimer, inhibits cigarette smoke-induced cell apoptosis in lungs by improving mitochondrial function. Acta Pharmacol Sin. 2014;35(6):779-91.

33. Iwai $K$, Kondo T, Watanabe M, Yabu T, Kitano T, Taguchi Y, Umehara H, Takahashi A, Uchiyama T, Okazaki T. Ceramide increases oxidative damage due to inhibition of catalase by caspase-3-dependent proteolysis in $\mathrm{HL}-60$ cell apoptosis. J Biol Chem. 2003;278(11):9813-22.

34. Petrache I, Medler TR, Richter AT, Kamocki K, Chukwueke U, Zhen L, Gu Y, Adamowicz J, Schweitzer KS, Hubbard WC, et al. Superoxide dismutase protects against apoptosis and alveolar enlargement induced by ceramide. Am J Physiol Lung Cell Mol Physiol. 2008;295(1):L44-53.

35. Uhlig S, Gulbins E. Sphingolipids in the lungs. Am J Respir Crit Care Med. 2008;178(11):1100-14.

36. He Z, Du L, Ke Y, Wen C, Zhang Y. PP2ACalpha of alveolar macrophages is a novel protective factor for LPS-induced acute respiratory distress syndrome. Inflammation. 2019;42(3):1004-14.

37. Grassme H, Carpinteiro A, Edwards MJ, Gulbins E, Becker KA. Regulation of the inflammasome by ceramide in cystic fibrosis lungs. Cell Physiol Biochem. 2014;34(1):45-55

38. Reunanen N, Westermarck J, Hakkinen L, Holmstrom TH, Elo I, Eriksson JE, Kahari VM. Enhancement of fibroblast collagenase (matrix metalloproteinase-1) gene expression by ceramide is mediated by extracellular signal-regulated and stress-activated protein kinase pathways. J Biol Chem. 1998;273(9):5137-45.

39. Kida H, Mucenski ML, Thitoff AR, Le Cras TD, Park KS, Ikegami M, Muller W, Whitsett JA. GP130-STAT3 regulates epithelial cell migration and is required for repair of the bronchiolar epithelium. Am J Pathol. 2008;172(6):1542-54.

40. Zheng L, Dong H, Zhao W, Zhang X, Duan X, Zhang H, Liu S, Sui G. An airliquid Interface organ-level lung microfluidics platform for analysis on molecular mechanisms of cytotoxicity induced by cancer-causing fine particles. ACS Sens. 2019;4(4):907-17.

\section{Publisher's Note}

Springer Nature remains neutral with regard to jurisdictional claims in published maps and institutional affiliations.
Ready to submit your research? Choose BMC and benefit from:
- fast, convenient online submission
- thorough peer review by experienced researchers in your field
- rapid publication on acceptance
- support for research data, including large and complex data types
- gold Open Access which fosters wider collaboration and increased citations
- maximum visibility for your research: over $100 \mathrm{M}$ website views per year
At BMC, research is always in progress.
Learn more biomedcentral.com/submissions 